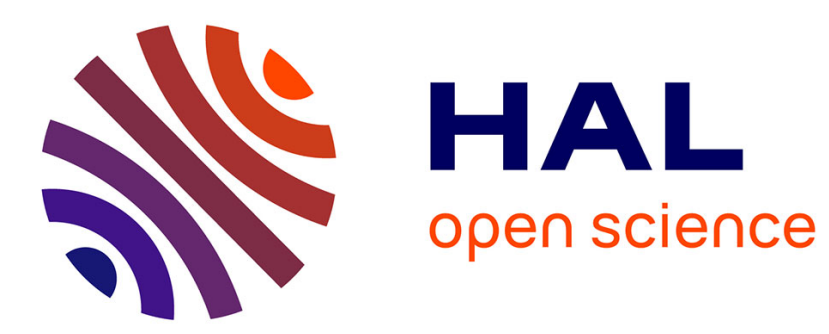

\title{
Analytical Modeling of Static Converters for optimal sizing of on-board electrical systems
}

Hieu Nguyen Huu, Laurent Gerbaud, Nicolas Rétière, James Roudet, Frédéric Wurtz

\section{- To cite this version: \\ Hieu Nguyen Huu, Laurent Gerbaud, Nicolas Rétière, James Roudet, Frédéric Wurtz. Analytical Modeling of Static Converters for optimal sizing of on-board electrical systems. VPPC 2010, Mar 2010, Lille, France. hal-00609598}

\section{HAL Id: hal-00609598 https://hal.science/hal-00609598}

Submitted on 19 Jul 2011

HAL is a multi-disciplinary open access archive for the deposit and dissemination of scientific research documents, whether they are published or not. The documents may come from teaching and research institutions in France or abroad, or from public or private research centers.
L'archive ouverte pluridisciplinaire HAL, est destinée au dépôt et à la diffusion de documents scientifiques de niveau recherche, publiés ou non, émanant des établissements d'enseignement et de recherche français ou étrangers, des laboratoires publics ou privés. 


\title{
Analytical Modeling of Static Converters for optimal sizing of on-board electrical systems
}

\author{
Hieu NGUYEN HUU, Laurent GERBAUD, Nicolas RETIERE, James ROUDET, Frederic WURTZ \\ GRENOBLE ELECTRICAL ENGINEERING LABORATORY (G2Elab) \\ UMR 5269 Grenoble INP-UJF-CNRS \\ ENSE3-BP 46 - 38402 St Martin D'Hères Cedex, FRANCE \\ E-mail: (Hieu.Nguyen-Huu; Laurent.Gerbaud; Nicolas.Retiere; James.Roudet; Frederic.Wurtz)@g2elab.grenoble-inp.fr
}

\begin{abstract}
Power electronics converters can generate a high level of harmonic perturbations on on-board electrical systems (planes, ships, road vehicles...). For the optimal sizing of these systems, harmonics must be known to select the best components (generator, filter...) that will limit their effects. In the paper, an analytical frequency domain modeling is proposed to accurately compute the harmonics generated the static converters. Because no numerical simulation is used, the presented approach is fast, accurate and applicable for optimal sizing or sensibility analysis. It is also valid for every kind of static converters. It is illustrated by its application to the sizing of an AC/DC power converter used for connecting electrical generators to DC on-board networks.
\end{abstract}

\section{INTRODUCTION}

Three-phase diode bridge rectifiers are often used in onboard systems (planes, ships, road vehicles...). Unfortunately, those converters also generate unwanted perturbations, especially electromagnetic perturbations in both common and differential conduction modes. Then, the design objectives of on-board systems shall include efficiency, mass or cost criteria but also shall take into account EMC (Electro Magnetic Compatibility) standards (for example [1]).

Numerical time simulation combined with FFT analysis can be used to calculate harmonics generated by power electronics converters [2]. This approach can be simply applied for modeling purposes and many algorithms have been developed to improve the quality of the results and to speed up the convergence [3],[4]. However, optimal design requires the use of optimization techniques and consequently numerous evaluations. If the evaluation consists in a FFT analysis following a time simulation then the optimal design may become very time consuming. In addition to that, if the system parameters change during the optimization, it might be difficult to manage correctly both the time simulation (e.g. the natural commutation times) and the parameters of the FFT algorithm (e.g. the window size). This generally gives wrong results. Thus a combined approach of time simulation and FFT is not suitable for the optimal design model of on-board electrical systems including numerous power electronics converters. Analytical modeling is preferred.
Several analytical harmonic modelings exist in the literature [5]-[8]. However, they often present some very restricting assumptions such as:

- resistive voltage drops are neglected at the input of the power converter [5],[6],

- only the modeling of controlled converters can be carried out [7],

- the modeling uses difficult-to-apply mathematical transformations [8].

Theses limitations have motivated the authors of the paper to develop a new approach which would be usable for every kind of static converter, especially the uncontrolled diode bridges which are very difficult to model because of the difficulty to know the switching times. This approach is fast, accurate, suitable for optimal design and easy to use. Basically, it is made of three steps:

- describing the converter by time-differential equations,

- calculating the switching times,

- computing the harmonics from the time-differential equations, the state variable values at the commutation times and the switching times.

The model will be used for the optimal design of an $\mathrm{AC} / \mathrm{DC}$ converter used for the $\mathrm{DC}$ generation in transport vehicles [9]. The generation system is made of a three-phase synchronous generator connected to the primary energy sources (amplitude Em, frequency fr $=\mathrm{wr} /(2 . \pi)$ ), a rectifier and a capacitor Cf on the DC link (Fig.1). The objective is to minimize the global mass of the power channel while fulfilling the DC output and the AC input harmonic standards.

In the next section, the modeling method is detailed step by step. The results given by the model are analyzed in section III.

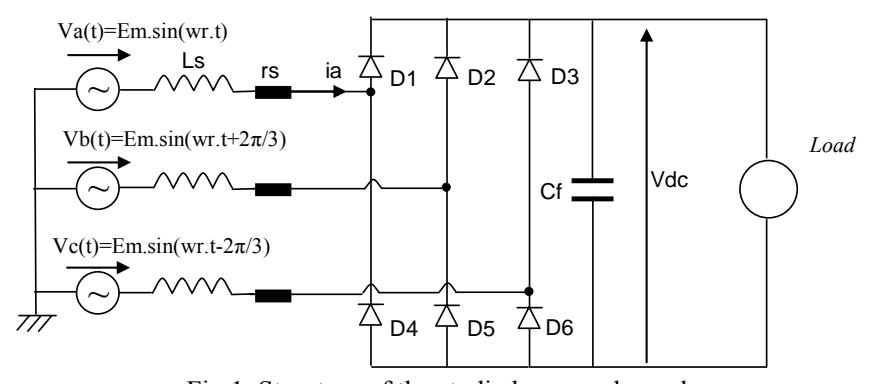

Fig.1. Structure of the studied power channel 


\section{MODELING METHOD}

The following assumptions are made:

- the static converters operate in periodic steady state,

- the switches are ideal (at on state they are represented by a simple short-circuit and at off state by an open circuit), and their commutations are instantaneous,

- the passive components are linear.

It should be noted that the proposed approach is adapted to converters using uncontrolled or controlled commutation devices.

The approach is made of three steps:

- writing of the time-differential equations describing the operation of the power converter (II.A),

- computation of the switching times by the solving of a set of non-linear equations (II.B),

- Fourier-Transform of the time-differential equations (II.C).

\section{A. Describing the converter by time-differential equations}

According to the general laws ruling electrical circuits, the time-differential equations describing the converter can be expressed by:

$$
\begin{gathered}
\dot{X}(t)=A(t) \cdot X(t)+B(t) \cdot U(t) \\
Y(t)=C(t) \cdot X(t)+D(t) \cdot U(t)
\end{gathered}
$$

(Elements description of these equations is presented in the table I.)

A power converter operates periodically with a period $T$. Thus:

$$
\begin{aligned}
& A(t)=A(t+T) ; B(t)=B(t+T) ; \\
& C(t)=C(t+T) \text { and } D(t)=D(t+T) \\
& X(t)=X(t+T) \text { and } Y(t+T)=Y(t) ;
\end{aligned}
$$

Over an operating period, the converter topology changes because of the commutations. On the other hand, it is assumed that the passive component values are constant. Thus, the matrixes $A, B, C, D$ depend only on the topology but are constant for a given topology. For these reasons, the time-differential equations of each configuration $k$ can be written as:

$$
\begin{aligned}
& \dot{X}_{k}(t)=A_{k} \cdot X_{k}(t)+B_{k} \cdot U(t) \\
& Y_{k}(t)=C_{k} \cdot X_{k}(t)+D_{k} \cdot U(t)
\end{aligned}
$$

where $k=1 . . N s w$,

with Nsw: total number of configurations encountered during the converter operating over a period.

During configuration $k$, the time $t$ runs as: $t_{k-1}<t<t_{k}$.

Over a period, the time-differential equations are given by the time-addition of each phase:

$$
\begin{aligned}
X(t) & =\sum_{k=1}^{N s w} X_{k}(t) \cdot \operatorname{wind}\left(t_{k-1}, t_{k}\right) \\
Y(t) & =\sum_{k=1}^{N s w} Y_{k}(t) \cdot w i n d\left(t_{k-1}, t_{k}\right)
\end{aligned}
$$

with $\operatorname{wind}\left(t_{k-1}, t_{k}\right)= \begin{cases}1 & \text { if } \quad\left(t_{k-1}<t<t_{k}\right) \\ 0 & \text { otherwise }\end{cases}$
TABLE I

ELEMENTS OF THE TIME-DIFFERENTIAL EQUATIONS

\begin{tabular}{|c|l|c|}
\hline Nom & \multicolumn{1}{|c|}{ Description } & Dimension \\
\hline$X$ & Time-differential vector & $\mathrm{n} \times 1$ \\
\hline$Y$ & Output vector & $\mathrm{p} \mathrm{x} \mathrm{1}$ \\
\hline$U$ & Input vector & $\mathrm{m} \times 1$ \\
\hline$A$ & State-space matrix & $\mathrm{n} \times \mathrm{n}$ \\
\hline$B$ & Input matrix & $\mathrm{n} \times \mathrm{m}$ \\
\hline$C$ & Output Matrix & $\mathrm{n} \times \mathrm{n}$ \\
\hline$D$ & Coupling Matrix & $\mathrm{p} \mathrm{x} \mathrm{n}$ \\
\hline$t$ & Time & 1 \\
\hline
\end{tabular}

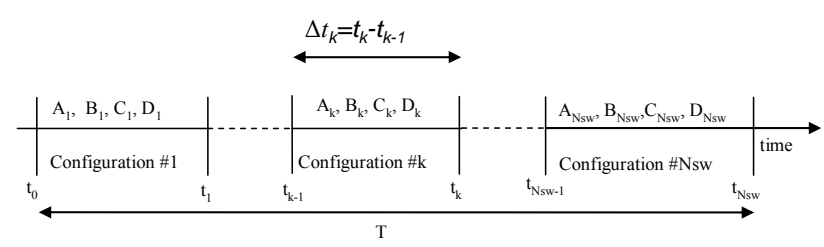

Fig.2. Representation of the converter configurations over an operating period

\section{B. Calculating the switching times}

\section{Solution of the time differential equations}

For configuration $\# k$, the solution of equations (3) and (4) is given by [10], [11]:

$$
\begin{gathered}
X_{k}(t)=e^{A_{k} \cdot\left(t-t_{k-1}\right)} \cdot X_{k}\left(t_{k-1}\right)+\int_{t_{k-1}}^{t_{k}} e^{A_{k} \cdot(t-\tau)} \cdot B_{k} \cdot U(\tau) \cdot d \tau \\
Y_{k}(t)=\mid \begin{array}{l}
C_{k}\left(e^{A_{k} \cdot\left(t-t_{k-1}\right)} \cdot X_{k}\left(t_{k-1}\right)\right. \\
\left.+\int_{t_{k-1}}^{t_{k}} e^{A_{k} \cdot(t-\tau)} \cdot B_{k} \cdot U(\tau) \cdot d \tau\right)+D_{k} \cdot U(t)
\end{array}
\end{gathered}
$$

It should be noted that it is not necessary to calculate expression (8). Indeed, the components $Y_{k}$ are given by a matrix combination of the time-differential vectors $X_{k}$ $(\mathrm{k}=1$..Nsw). Thus, only expression (7) has to be solved. For that purpose, the time intervals $\left[t_{k}, t_{k+1}\right]$ and the initial values $\mathrm{X}_{\mathrm{k}}\left(\mathrm{t}_{\mathrm{k}-1}\right)$ have to be pre-determined.

\section{Determination of the time intervals and the initial values}

The time-differential vectors are time-continuous. So, it is possible to write (see Fig. 2):

$$
X_{k}\left(t_{k-1}\right)=X_{k-1}\left(t_{k-1}\right)
$$

As a consequence, the number of unknown variables to compute the time-differential vector is equal to $(N s w+1+$ $n)$ :

$-N s w+1$ is the number of switching times $\left(\mathrm{t}_{0}, \mathrm{t}_{1}, . ., \mathrm{T}_{\mathrm{Nsw}}\right)$

$-n$ is the dimension of the time-differential vector $\mathrm{X}$.

The $(N s w+1+n)$ equations required to compute the unknown variables constitute a set of implicit equations which will have to be solved.

To write this equation system, the assumption of steadystate operation is first considered. It can be translated into an equality between the values of the time-differential vector at the beginning and the end of the operating period:

$$
X_{1}\left(t_{0}\right)=X_{N s w}\left(t_{N s w}\right)
$$




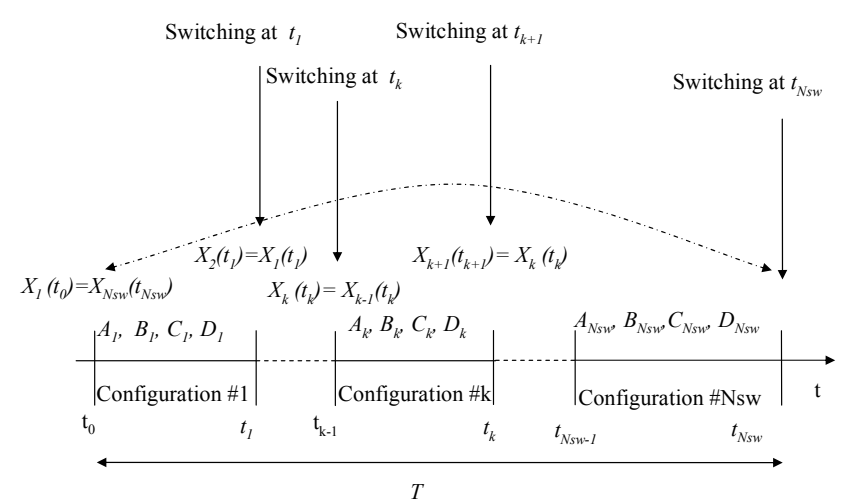

Fig.3: State-space representation over an operating period

Commutation_criterion $=\mathrm{i}\left(\mathrm{t}_{\mathrm{k}}\right)=0$

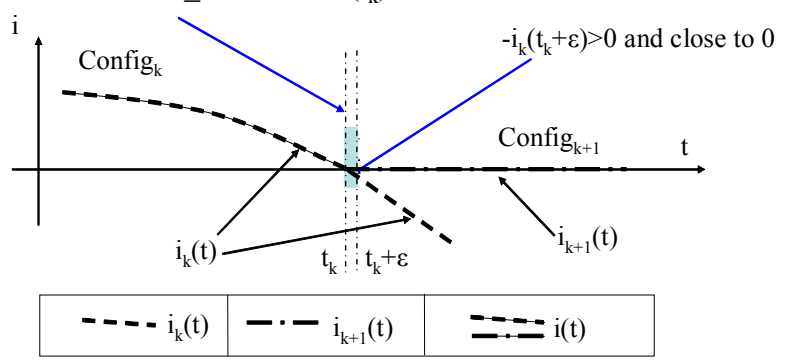

Fig. 4. Commutation criterion for the turning off of a diode

(i $(\mathrm{t})$ is $\mathrm{i}_{\mathrm{k}}(\mathrm{t})$ if $\mathrm{t}<\mathrm{t}_{\mathrm{k}}$ and $\mathrm{i}_{\mathrm{k}+1}(\mathrm{t})$ if $\left.\mathrm{t}>\mathrm{t}_{\mathrm{k}}\right)$

This relation gives $n$ equations because of the dimension of vector $X$

Another relation to be respected concerns the definition of the operating period. It is given by:

$$
t_{N s w}-t_{0}=T
$$

And, besides, at every configuration change $t_{k}$, a set of equations has to be respected. It concerns the currents and voltages of all the switches which are commuting [12]. Fig.4 shows the example of the turning off of a diode at $t_{k}$. At this time, a switching criterion has to be respected. It says that the current is equal to zero at $t_{k}$ and negative (but very closed to zero) just after $t_{k}$ i.e. $t_{k}+\varepsilon$ where $\varepsilon$ is less than some percents of the smallest configuration duration.

The switching criterion constitute an other set of $N s w$ implicit equations: $\mathrm{g}_{\mathrm{k}}\left(\mathrm{t}_{\mathrm{k}}\right)=0 \quad(k=1 . . N s w)$

Finally, the complete system of implicit equations required to compute the time-differential vector is given by:

$$
\left\{\begin{array}{l}
X_{1}\left(t_{0}\right)=X_{N s w}\left(t_{N s w}\right) \\
t_{N s w}-t_{0}=T \\
g_{k}\left(t_{k}\right)=0 \quad(k=1 . . N s w)
\end{array}\right.
$$

where the unknown variables are $t_{0}, t_{1}, . ., t_{N s w}, X_{1}\left(t_{0}\right)$

This set of equations is solved using dedicated methods for non-linear systems such as Newton-Raphson [13].

\section{Computing the harmonics from the time-differential equations and the duration of each phase}

For every configuration $\# \mathrm{k}(\mathrm{k}=1 . . \mathrm{Nsw})$, the time-differential vector $\mathrm{X}_{\mathrm{k}}(\mathrm{t})$ and the beginning times $\mathrm{t}_{\mathrm{k}-1}$ are known from equations (7) and
(13). The output harmonics can then be easily calculated using the Fourier series. The authors propose an other approach based on the Fourier Transform.

Equations (5) and (6) give:

$$
\begin{aligned}
& Y(t)=\sum_{k=1}^{N s w} Y_{k}(t) . \text { wind }\left(t_{k-1}, t_{k}\right) \\
& =\mid \begin{array}{l}
\sum_{k=1}^{N s w} C_{k} \cdot X_{k}(t) \cdot \text { wind }\left(t_{k-1}, t_{k}\right) \\
+\sum_{k=1}^{N s w} D_{k} \cdot U(t) \cdot \text { wind }\left(t_{k-1}, t_{k}\right)
\end{array}
\end{aligned}
$$

Thus, the Fourier Transform of $Y$ is given by:

$$
\begin{aligned}
T F(Y)(f) & =\mid \begin{array}{l}
T F\left[\sum_{k=1}^{N s w} C_{k} \cdot X_{k}(t) \cdot w i n d\left(t_{k-1}, t_{k}\right)\right](f) \\
+T F\left[\sum_{k=1}^{N s w} D_{k} \cdot U(t) \cdot w i n d\left(t_{k-1}, t_{k}\right)\right](f)
\end{array} \\
& =\mid \begin{array}{l}
\sum_{k=1}^{N s w} C_{k} \cdot T F\left[X_{k}(t) \cdot \operatorname{wind}\left(t_{k-1}, t_{k}\right)\right](f) \\
+\sum_{k=1}^{N s w} D_{k} \cdot T F\left[U(t) \cdot \operatorname{wind}\left(t_{k-1}, t_{k}\right)\right](f)
\end{array}
\end{aligned}
$$

For power electronics converters, the vector $\mathrm{U}(\mathrm{t})$ is often made of voltage or current sources which are constant or sinusoidally time-varying; for example: $U(t)=V d c$ or $U(t)=V 0 . \sin (2 . \pi . f . t))$.

Thus, the term given by: $\sum_{k=1}^{N s w} D_{k} \cdot T F\left[U(t) \cdot \operatorname{wind}\left(t_{k-1}, t_{k}\right)\right](f)$ can be symbolically calculated by using the Fourier Transform definition. Hence, only the symbolical computation of $\operatorname{TF}\left[X_{k}(t)\right.$.wind $\left.\left(t_{k-1}, t_{k}\right)\right](f)$ is not straightforward.

Equation (3) gives the time derivation of the timedifferential vector over $\left[t_{k-1}, t_{k}\right]$ :

$$
\left.\dot{X}_{k}(t) \cdot \operatorname{wind}\left(t_{k-1}, t_{k}\right)=\mid \begin{array}{l}
A_{k} \cdot X_{k}(t) \cdot \operatorname{wind}\left(t_{k-1}, t_{k}\right) \\
+B_{k} \cdot U(t) \cdot \operatorname{wind}\left(t_{k-1}, t_{k}\right)
\end{array}\right)
$$

The Fourier Transform of the left side of (16) is given by using the Fourier Transform expression:

$$
\begin{aligned}
& T F\left[\dot{X}_{k}(t) \text { wind }\left(t_{k-1}, t_{k}\right)\right](f) \\
& =\mid \begin{array}{l}
-X_{k}\left(t_{k-1}\right) \cdot e^{-j \cdot 2 \pi \cdot f \cdot t_{k-1}}+X_{k}\left(t_{k}\right) \cdot e^{-j \cdot 2 \pi \cdot f \cdot t_{k}} \\
+j \cdot 2 \cdot \pi \cdot f \cdot T F\left[X_{k}(t) \cdot w i n d\left(t_{k-1}, t_{k}\right)\right](f)
\end{array}
\end{aligned}
$$

Equations (16) and (17) finally give:

$-X_{k}\left(t_{k-1}\right) \cdot e^{-j \cdot 2 \pi \cdot f \cdot t_{k-1}}$
$+X_{k}\left(t_{k}\right) \cdot e^{-j \cdot 2 \pi \cdot f \cdot t_{k}}+j \cdot 2 \cdot \pi \cdot f$
$\operatorname{TF}\left[X_{k}(t) \cdot \operatorname{wind}\left(t_{k-1}, t_{k}\right)\right](f)$$|=| \begin{aligned} & A_{k} \cdot \operatorname{TF}\left[X_{k}(t) .\right. \\ & \left.\operatorname{wind}\left(t_{k-1}, t_{k}\right)\right](f)+B_{k} . \\ & \operatorname{TF}\left[U(t) \cdot \operatorname{wind}\left(t_{k-1}, t_{k}\right)\right](f)\end{aligned}$

Let define $T F_{k}(f)=T F\left[X_{k}(t) \cdot \operatorname{wind}\left(t_{k-1}, t_{k}\right)\right](f)$

$$
\text { and } M F_{k}=\left[\begin{array}{ccc}
j .2 . \pi \cdot f & 0 & 0 \\
0 . & & 0 \\
0 & 0 & j .2 . \pi . f
\end{array}\right]=j \cdot 2 . \pi \cdot f . I_{n d}
$$


(with $n d=\operatorname{Dim}\left(M F_{k}\right)=\operatorname{Dim}\left(A_{k}\right)$ )

Equation (18) becomes:

$$
\left(M F_{k}-A_{k}\right) \cdot T F_{k}(f)=\mid \begin{aligned}
& B_{k} \cdot T F\left[U(t) \cdot \text { wind }\left(t_{k-1}, t_{k}\right)\right](f) \\
& +X_{k}\left(t_{k-1}\right) \cdot e^{-j \cdot 2 \pi \cdot f \cdot t_{k-1}} \\
& -X_{k}\left(t_{k}\right) \cdot e^{-j \cdot 2 \pi \cdot f \cdot t_{k}}
\end{aligned}
$$

If matrix $\left(M F_{k}-A_{k}\right)$ is invertible, the value of $T F_{k}(f)$ is given by:

$$
T F_{k}(f)=\mid \begin{aligned}
& \left(M F_{k}-A_{k}\right)^{-1} \cdot B_{k} \cdot T F\left[U(t) \cdot w i n d\left(t_{k-1}, t_{k}\right)\right](f) \\
& +\left(M F_{k}-A_{k}\right)^{-1} \cdot\left[X_{k}\left(t_{k-1}\right) \cdot e^{-j \cdot 2 \pi \cdot f \cdot t_{k-1}}\right. \\
& \left.-X_{k}\left(t_{k}\right) \cdot e^{-j \cdot 2 \pi \cdot f \cdot t_{k}}\right]
\end{aligned}
$$

The Fourier Transform of $Y$ can then be calculated and the amplitude of the $\mathrm{n}^{\text {th }}$ harmonic is defined by:

$$
\begin{aligned}
& -n=0, S_{0}=f r .|T F(Y)(0)| \\
& -n>0, S_{n}=2 . f r .|T F(Y)(n . f r)| \\
& \text { with } f r=1 / T
\end{aligned}
$$

As a conclusion, the whole approach described in sections $\mathrm{A}, \mathrm{B}$ and C) does not need any numerical simulation and is easily applicable for the modelling of any kind of power converters operating in steady-state.

\section{APPLICATION TO AN AC/DC POWER CONVERTER}

To illustrate the proposed method, the harmonic study of a diode rectifier is presented and the results obtained by the approach of section II are compared with numerical simulation performed by Saber. The studied case is shown in Fig. 1. The load is represented by current $i l$.

\section{A. Modeling}

\section{Operating phases}

The converter operating is defined by twelve configurations as seen in table II. These configurations succeed over a period $T=2 \pi / w r$.

TABLE II

SYSTEM OPERATION OVER A PERIOD

\begin{tabular}{|c|c|c|c|c|c|c|}
\hline Conf. & $\begin{array}{c}\text { Diode } \\
\mathbf{1}\end{array}$ & $\begin{array}{c}\text { Diode } \\
\mathbf{2}\end{array}$ & $\begin{array}{c}\text { Diode } \\
\mathbf{3}\end{array}$ & $\begin{array}{c}\text { Diode } \\
\mathbf{4}\end{array}$ & $\begin{array}{c}\text { Diode } \\
\mathbf{5}\end{array}$ & $\begin{array}{c}\text { Diode } \\
\mathbf{6}\end{array}$ \\
\hline $\mathbf{1}$ & ON & OFF & OFF & OFF & OFF & ON \\
\hline $\mathbf{2}$ & ON & OFF & OFF & OFF & ON & ON \\
\hline $\mathbf{3}$ & ON & OFF & OFF & OFF & ON & OFF \\
\hline $\mathbf{4}$ & ON & OFF & ON & OFF & ON & OFF \\
\hline $\mathbf{5}$ & OFF & OFF & ON & OFF & ON & OFF \\
\hline $\mathbf{6}$ & OFF & OFF & ON & ON & ON & OFF \\
\hline $\mathbf{7}$ & OFF & OFF & ON & ON & OFF & OFF \\
\hline $\mathbf{8}$ & OFF & ON & ON & ON & OFF & OFF \\
\hline $\mathbf{9}$ & OFF & ON & OFF & ON & OFF & OFF \\
\hline $\mathbf{1 0}$ & OFF & ON & OFF & ON & OFF & ON \\
\hline $\mathbf{1 1}$ & OFF & ON & OFF & OFF & OFF & ON \\
\hline $\mathbf{1 2}$ & ON & ON & OFF & OFF & OFF & ON \\
\hline
\end{tabular}

Configuration \# 1

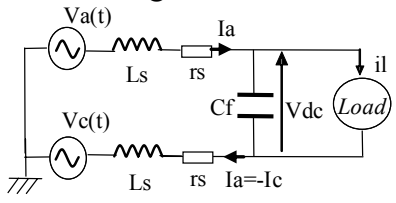

Configuration \# 2

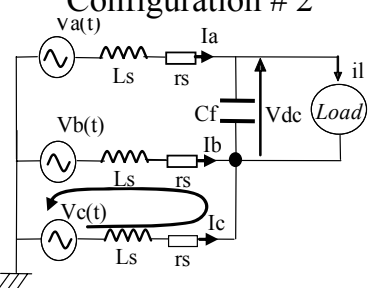

Fig.5. System Operation for configurations \#1 and \#2

There are two operating types: normal conduction (two diodes operate), commutation (three diodes operate, with anode overlap). Only configurations \#1 and \#2 will be detailed below. Indeed, the other configurations can be written similarly. Only a cyclic permutation of indexes has to be performed.

Configurations \#1 and \#2 correspond to the topologies of the converter shown in Fig.5.

\section{Time-differential equations}

The time-differential vector is made of the input current $\mathrm{Ia}(\mathrm{t})$ and the DC output voltage $\operatorname{Vdc}(\mathrm{t})$. The time-differential equations are:

- Over the time interval $\left[t_{0}, t_{1}\right]$ :

$$
\begin{aligned}
\left(\dot{X}_{1}\right) & =\left(\begin{array}{c}
\dot{I a_{1}} \\
\dot{\dot{d}_{c_{1}}}
\end{array}\right)=\left(\begin{array}{cc}
-r s / L s & -1 /(2 \cdot L s) \\
1 / C f & 0
\end{array}\right) \cdot\left(\begin{array}{c}
I a_{1} \\
V d c_{1}
\end{array}\right)+\left(\begin{array}{c}
1 /(2 \cdot L s) \\
1 / C f
\end{array}\right) \cdot\left(\begin{array}{c}
V a-V c \\
I l
\end{array}\right) \\
& - \text { Over the time interval }\left[t_{1}, t_{2}\right]: \\
\left(\dot{X}_{2}\right) & =\left(\begin{array}{c}
I a_{2} \\
V \dot{d} c_{2}
\end{array}\right)=\left(\begin{array}{cc}
-r s / L s & -2 /(3 . L s) \\
1 / C f & 0
\end{array}\right) \cdot\left(\begin{array}{c}
I a_{2} \\
V d c_{2}
\end{array}\right)+\left(\begin{array}{c}
1 / L s \\
1 / C f
\end{array}\right) \cdot\left(\begin{array}{c}
V a \\
I l
\end{array}\right)
\end{aligned}
$$

Similar expressions can be obtained for time intervals $\left[t_{2}, t_{3}\right] \ldots\left[t_{11}, t_{12}\right]$.

\section{Solving the time-differential equations in the time domain a. Expression of the time-differential vectors}

Equations (23) and (24) are symbolically solved by using Maple. The resulting expressions of $I a_{l}, V d c_{l}$ are not given in this because of the lack of space on the page. $\mathrm{Ia}_{1}$ and $V d c_{1}$ depend on the system parameters (i.e.: $r s, L s$ and $C f$ ) and the initial values $I a_{1}\left(t_{0}\right), V d c_{1}\left(t_{0}\right)$. Similar expressions of Ia and $\mathrm{Vdc}$ can be obtained for time intervals $\left[t_{1}, t_{2}\right] \ldots\left[t_{11}, t_{12}\right]$.

The required information to compute these expressions are summarized in table III.

b. Determination of the switching times and the initial values

The time-differential vector is continuous. So, by considering that:

\section{$I a_{2}\left(t_{1}\right)=I a_{1}\left(t_{1}\right) \ldots I a_{k+1}\left(t_{k}\right)=I a_{k}\left(t_{k}\right) \ldots I a_{12}\left(t_{11}\right)=I a_{11}\left(t_{11}\right)$}

$V d c_{2}\left(t_{1}\right)=V d c_{1}\left(t_{1}\right) \ldots V d c_{k+1}\left(t_{k}\right)=V d c_{k}\left(t_{k}\right) \ldots d c_{12}\left(t_{11}\right)=V d c_{11}\left(t_{11}\right)$ the time-differential vector is only a function of $\operatorname{Ia}_{l}\left(t_{0}\right)$, $V d c_{1}\left(t_{0}\right)$ and $t_{0}, t_{1}, \ldots t_{12}$. Finally, there are only 15 unknown variables. The 15 corresponding equations required to compute their values are now listed.

The periodicity of the operating mode of the diode rectifier is defined by equations (25), (26) and (27):

$$
\begin{gathered}
\mathrm{t}_{12}-\mathrm{t}_{0}=\mathrm{T} \\
\mathrm{Ia}_{12}\left(\mathrm{t}_{12}\right)=\mathrm{Ia}_{1}\left(\mathrm{t}_{0}\right) \\
\mathrm{Ia}_{12}\left(\mathrm{t}_{12}\right)=\mathrm{Ia}_{1}\left(\mathrm{t}_{0}\right)
\end{gathered}
$$


TABLE III

REQUIRED INFORMATION FOR THE COMPUTATION OF EACH CONFIGURATION

\begin{tabular}{|c|c|c|c|c|}
\hline $\begin{array}{c}\text { Time } \\
\text { Interval }\end{array}$ & {$\left[\mathrm{t}_{0}, \mathrm{t}_{1}\right]$} & {$\left[\mathrm{t}_{1}, \mathrm{t}_{2}\right]$} & $\cdots$ & {$\left[\mathrm{t}_{11}, \mathrm{t}_{12}\right]$} \\
\hline $\mathrm{X}$ & $\mathrm{Ia}_{1}, \mathrm{Vdc}_{1}$ & $\mathrm{Ia}_{2}, \mathrm{Vdc}_{2}$ & $\ldots$ & $\mathrm{Ia}_{12}, \mathrm{Vdc}_{12}$ \\
\hline $\begin{array}{c}\text { Beginning } \\
\text { time }\end{array}$ & $\mathrm{t}_{0}$ & $\mathrm{t}_{1}$ & $\ldots$ & $\mathrm{t}_{12}$ \\
\hline Initial value & $\begin{array}{c}\mathrm{Ia}_{1}\left(\mathrm{t}_{0}\right) \\
\mathrm{Vdc}_{1}\left(\mathrm{t}_{0}\right)\end{array}$ & $\begin{array}{c}\mathrm{Ia}_{2}\left(\mathrm{t}_{1}\right) \\
\mathrm{Vdc}_{2}\left(\mathrm{t}_{1}\right)\end{array}$ & $\ldots$ & $\mathrm{Ia}_{12}\left(\mathrm{t}_{11}\right)$ \\
$\mathrm{Vdc}_{12}\left(\mathrm{t}_{11}\right)$
\end{tabular}

Switching conditions can also be expressed.

At the end of the time interval $\left[t_{0}, t_{l}\right]$, the voltage across the terminals of diode D6 has to be equal to zero (tends to become positive):

$$
V D 6_{1}(t)=-V d c\left(t_{1}\right)-r s . i a\left(t_{1}\right)-L s \cdot \frac{\operatorname{dia}\left(t_{1}\right)}{d t}+v a\left(t_{1}\right)-v b\left(t_{1}\right)=0
$$

From equations (23) and (28), it is possible to write the first switching condition:

$$
\frac{V d c\left(t_{1}\right)}{2}+\frac{3}{2} \cdot \operatorname{Em} \cdot \sin \left(w r \cdot t_{1}+\frac{2 \pi}{3}\right)=0
$$

At the end of the time interval $\left[t_{1}, t_{2}\right]$, the current through diode D6 has to be equal to zero (it tends to become negative):

$$
i D 6_{2}\left(t_{2}\right)=I c_{2}\left(t_{2}\right)=0
$$

Current $I c_{2}(t 2)$ is calculated from the following equations:

$$
(V b(t)-V c(t))-r s . I t_{2}(t)-L s \cdot \frac{d t_{2}(t)}{d t}=0
$$

with $I t_{2}=I b_{2}-I c_{2}$ and $I a_{2}=I b_{2}+I c_{2}$.

thus:

$$
I t_{2}(t)=\mid \begin{aligned}
& -I c_{2}\left(t_{1}\right) \cdot e^{-\frac{r s}{L S}\left(t-t_{1}\right)} \\
& -e^{-\frac{r s}{L s}\left(t-t_{1}\right)} \cdot \frac{E m}{r s^{2}+L s^{2} \cdot w r^{2}} \cdot\left[\begin{array}{c}
r s\left[\sin \left(\frac{t_{2}}{w r}+\frac{2 \pi}{3}\right)-\sin \left(\frac{t_{2}}{w r}-\frac{2 \pi}{3}\right)\right]- \\
w r \cdot L s\left[\cos \left(\frac{t_{2}}{w r}+\frac{2 \pi}{3}\right)-\cos \left(\frac{t_{2}}{w r}-\frac{2 \pi}{3}\right)\right]
\end{array}\right] \\
& +\frac{E m}{r s^{2}+L s^{2} \cdot w r^{2}} \cdot\left[\begin{array}{l}
R s\left[\sin \left(w r \cdot t+\frac{2 \pi}{3}\right)-\sin \left(w r \cdot t-\frac{2 \pi}{3}\right)\right]- \\
L s \cdot w r\left[\cos \left(w r \cdot t+\frac{2 \pi}{3}\right)-\cos \left(w r \cdot t-\frac{2 \pi}{3}\right)\right]
\end{array}\right]
\end{aligned}
$$

And:

$$
I c_{2}(t)=0.5 \cdot\left(I a_{2}(t)-I t_{2}(t)\right)
$$

It gives the second switching condition. The ten other conditions for configurations 3 to 12 can be obtained in the same way.

Finally, the implicit equations system to be solved is constituted by equations (25), (26), (27), and the 12 equations of the switching conditions for the 12 configurations.

4. Calculating the harmonics from the time differential equations and the duration of each phase

The aim is to calculate the harmonics of the input current $I a$ and the voltage $V d c$ across the DC bus.

Over an operating period, the time and frequency expressions of the input current are given by:

$$
I a(t)=\sum_{k=1}^{12} I a_{k} \cdot \operatorname{wind}\left(t_{k-1}, t_{k}\right)
$$

$$
\operatorname{Ia}(f)=\operatorname{TF}[\operatorname{Ia}(t)](f)=\sum_{k=1}^{12} \operatorname{TF}\left[\operatorname{Ia} a_{k} \cdot \operatorname{wind}\left(t_{k-1}, t_{k}\right)\right](f)
$$

Then, using the Fourier Transform of a windowed function given by (20), it is possible to know all the expressions of $T F\left[\operatorname{Ia} \cdot\right.$ wind $\left.\left(t_{k-1}, t_{k}\right)\right](f)(k=1 . .12)$.

The amplitude of the $\mathrm{n}^{\text {th }}$ harmonic of the input current is finally obtained by:

$$
\begin{aligned}
& >\mathrm{n}=0, I a_{0}=f r \cdot|\operatorname{Ia}(0)| \\
& >\mathrm{n}>0, I a_{n}=2 \cdot f_{r .}\left|\operatorname{Ia}\left(n \cdot f_{r}\right)\right|
\end{aligned}
$$

The harmonics of $V d c$ are determined by the same approach.

\section{B. Application}

As the model does not require any numerical simulation, it can be easily implemented in any computation software such as CADES [14], Matlab, or Mathcad, for optimization purpose. For our example, CADES is chosen because it offers a powerful panel of tools for optimal design of electrical systems. The value of the system parameters are:

$$
\begin{aligned}
& \mathrm{Em}=162 \mathrm{~V} \\
& \mathrm{wr}=2 . \pi .400 \mathrm{rad} / \mathrm{s} \\
& \mathrm{rs}=0.0136 \Omega \\
& \mathrm{Ls}=30 \mu \mathrm{H} \\
& \mathrm{Cf}=500 \mu \mathrm{F}
\end{aligned}
$$

The load feeding by the DC generation system is represented by a constant DC current and two alternative currents at high frequency. Both of them are supposed to represent the harmonic content generated by the load in addition to its DC component (see Fig. 6 below).

\section{Accuracy of the modeling results}

Fig.7 and Fig. 8 show a comparison between the results obtained by the proposed approach and a Saber-based FFT analysis. These figures illustrate the accuracy of the proposed approach. Indeed, the maximal value of the relative error is equal to $0.68 \%$ for the input current harmonics and $0.74 \%$ for the DC voltage harmonics. This error is defined by:

$$
\varepsilon h_{i}=\left|h a_{i}-h s_{i}\right| / \max \left(h a_{i}\right)_{i=0 . . N h}
$$

with $h a_{i}: \mathrm{i}^{\text {th }}$ harmonic given by the analytical model; $h s_{i}: \mathrm{i}^{\text {th }}$ harmonic given by the FFT analysis $N h$ : number of calculated harmonics

\section{Advantage for optimal sizing}

Besides accuracy, the proposed approach requires only $0.019 \mathrm{~s}$ to compute the harmonics whereas a Saber-based analysis requires $0.226 \mathrm{~s}$ (on a PC Intel Core ${ }^{\mathrm{TM}} 2$ Duo-3 GHz$3.25 \mathrm{~GB}$ Ram). This factor 12 constitutes a great advantage of the proposed method over the simulation to perform optimization as it reduces greatly the CPU time.

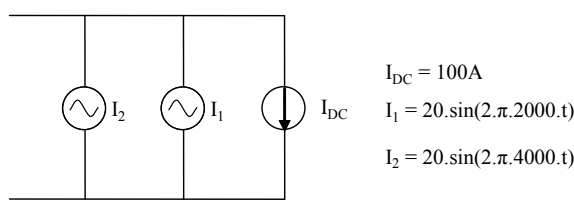

Fig.6: Model of the load connected to the DC bus 


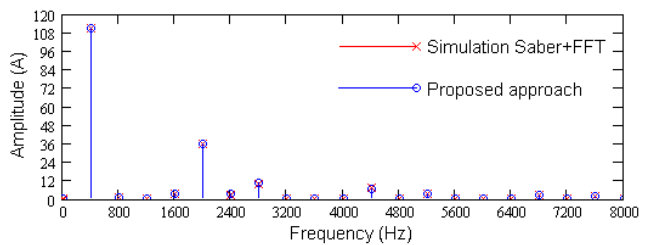

Fig. 7. Harmonic content of the input current Ia

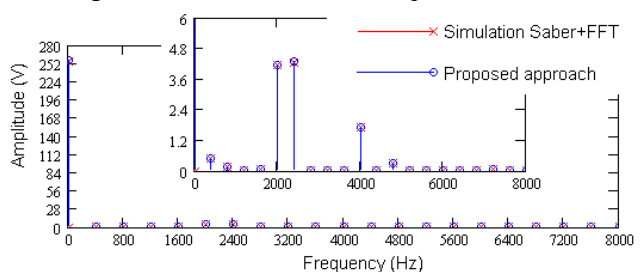

Fig. 8: Harmonic content of the DC output voltage Vdc

Moreover, the analytical expressions given by our model can be easily used to compute symbolically and accurately the sensitivity of the harmonics to the model parameters (rs, Ls, etc.) [14]. This is a great help for the optimal design because it enables the use of gradient-based optimization algorithm which are proved to be efficient and fast. Note that CADES allows to create automatically the calculation code of the gradients of any symbolic model.

\section{Optimal design results}

The model is used to size a real on-board generating unit as shown in Fig.1. The objectives are to reduce the weight of the unit. The design parameters are the generator and rectifier geometries and the capacitor value. The system must respect energy requirement (power delivery, limited current in the conductors...), mechanic and thermal constraints. In addition, the harmonic content of the DC voltage is limited by a standard (form $0 \mathrm{~Hz}$ to $15 \mathrm{MHz}$ ). Finally, there are 17 design parameters ( 8 continuous, 9 discrete) and 18 constraints (except the harmonics).

In this application, the gradient-based algorithms cannot be used because of discrete of design parameters. Thus, an evolutionary algorithm [15] is used to perform the optimization. At first, the optimization enables to decrease the total mass of the unit by around $20 \%$. Moreover, the CPU time required to perform the optimization is of course reduced of a factor 12 if our model is used for the evaluations instead of the Saber simulation. It means that only two hours are required instead of one computation day! There is no doubt about the interest of our modeling approach for designers of industrial on-board electrical systems.

\section{CONCLUSIONS}

In the paper, the authors have proposed a method to build analytical models of static converters in the frequency domain. The approach consists in using time differential equations formalism combined with Fourier Transform. The method has been applied to model and design an AC/DC generating unit which is encountered in many on-board systems such as vehicles or aircrafts.

The results prove the feasibility, accuracy and usability of the method. In addition to that, it has been implemented in a software framework which makes the work of design engineers faster and easier.

Last but not least, the method presented in this article can be used for any kind of power electronics converters, operating in continuous mode or not. This should open interesting ways for analyzing and designing modern electrical systems embedded in future transport vehicles.

\section{ACKNOWLEDGMENT}

This research is part of a project associating G2Elab with Laplace and Thales AES. The authors would like to thank all the partners for their contribution to the design of the generation unit. The authors would also like to thank JeanFrançois Lange for his greatly appreciated help.

\section{REFERENCES}

[1] H. Nguyen-Huu, N. Retière, F. Wurtz, X. Roboam, B. Sareni, D. Aléjo, "Optimal sizing of an embedded electrical system with an approach for limiting the search space”, COMPEL, 2009, Volume 28, Number 5, pp. 1141-1154.

[2] G. W. Chang, S. H. Lee, and Y. C. Chin, "Analyzing Input Harmonic Currents of a Six-pulse AC/DC Converter by an Efficient Time-domain Approach", Proceedings of the 1st IEEE Conference on Industrial Electronics and Applications (ICIEA'2006), pp.1-5.

[3] Y. C. Chin, G. W. Chang, "Efficient approach to characterizing harmonic currents generated by a cluster of three-phase AC/DC converters", IEE Proceedings: Electric power applications, ISSN 1350-2352, Vol. 153, No 5, 2006 , pags. 742-749.

[4] R.G. Bedrosian, J. Vlach, "An accelerated steady-state method for networks with internally controlled switches", IEEE Trans. on circuits and systems, 1992, vol. 39, $\mathrm{n}^{\circ} 7$, pp. 520-530.

[5] M.Grotzbach, J. Xu, "Line-side behaviour of three-phase diode rectifiers with reactance smoothing", European transactions on electrical power engineering, 1994, vol. 4, nº 1, pp. 35-42.

[6] J. G. Mayordomo, A. Carbonero, L. F. Beites, R. Asensi, and W Xu, "A Contribution Towards a General and Systematic Procedure for Modeling Line Commutated AC/DC Converters in the Harmonic Domain", IEEE Trans. on power delivery, 2009, vol. 24, n$^{\circ} 4$, pp. 2415-2427.

[7] J. Arrillaga, B.C. Smith, N.R. Watson, A.R. Wood, "Power System Harmonic Analysis”, 1997, John Wiley \& Sons.

[8] G. Carpinelli, F. Iacovone, A. Russo, P. Varilone, and P. Verde, "Analytical modeling for harmonic analysis of line current of vsi-fed drives", IEEE Trans. on power delivery, 2004, vol. 19, no. 3, pp. 1212-1224

[9] M. Käbisch, M. Heuer, G. Heideck, Z. A. Styczynski, “Energy management of vehicle electrical system with auxiliary power unit", 5th International IEEE Vehicle Power and Propulsion Conference, Dearborn,Sep.2009, pp.358 - 363.

[10] J. D’Azzo, J. Houpis, "Linear control system analysis and design", 4th ed. McGraw Hill Book Co, 1985

[11] P.R. Mugur, J. Roudet, J.C.Crebier, "Power electronic converter EMC analysis through state variable approach techniques", IEEE trans. on electromagnetic compatibility, 2001, vol. 43, no2, pp. 229238

[12] S. Bergeon, L. Gerbaud, J. Bigeon, F. Wurtz, "Towards an automatic approach for the design of static converters", IEEECOM.P.EL'98 (Workshop on COMputer in Power Electronics), Villa Erba, Como, Italy, July 19-22, 1998, pp 157-162

[13] W.H. Press, S.A. Teukolsky, W.T. Wetterling, B.P. Flannery, "Numerical recipes in $C$ : the art of scientific computing", ISBN 0521-431-08-5

[14] B. Delinchant, D. Duret, L Estrabaut, L. Gerbaud, H. Nguyen Huu, B. du Peloux, H.L. Rakotoarison, F. Verdiere, F. Wurtz " $A n$ Optimizer using the Software Component Paradigm for the Optimization of Engineering Systems”, COMPEL 2007, Volume 26, Issue 2, pp. 368-379

[15] T. Bäck, "Evolutionary Algorithms in Theory and Practice", 1996, Oxford University Press, New York. 